\title{
Formal Game Element Analysis of Rhythm Fighting Game
}

\section{Case Study: Rhythm Fighter, Welcome to The Factory, Skybolt Zack}

\author{
Adita Wening Octaviani ${ }^{1 *}$, Irfansyah Irfansyah ${ }^{2}$
}

\author{
${ }^{I}$ Institut Teknologi Bandung, Bandung \\ ${ }^{2}$ Institut Teknologi Bandung, Bandung \\ *Corresponding author.Email: aditawo@gmail.com
}

\begin{abstract}
Action Game is a type of game that is popular and much in demand among teenagers and children. One of the sub-genres of Action Game is Fighting Game, which is a battle game or duel between 2 or 1 character with many opponents. The different elements that appear in the Fighting Game genre are represented by the player's character, the setting of the game's location, and the missions. This study explores the characteristics, advantages, and disadvantages of several games with the Rhythm Fighting Game genre that teenagers and children mostly play. The focused analysis covers 3 Rhythm Fighting Games: Rhythm Fighter, Welcome to The Factory (WTF), and Skybolt Zack. The analysis is approached through the formal game elements with the Content Analysis method. Identification includes aspects of player interaction, goals, procedures, rules, assets, conflicts, boundaries, and goals in the game. The analysis results show the similarities that characterize the Rhythm Fighting Game from the "rules" of the gameplay defeating the enemy. Meanwhile, the indicators of the difference shown by the three games are in the theme of Rhythm Fighter, which is set in the lives of animals, WTF has the theme of life in a factory and laboratory, while Skybolt Zack has the theme of a future life ruled by robots. Interestingly, the fewer variety resources of the Rhythm Fighting Game, the greater limitations in the game. For example, Skybolt Zack and WTF, which only have two supporting equipment, make players' imaginations limited and less varied. Unlike the Rhythm Fighter, with a variety of resources that keep players curious and keep the game.
\end{abstract}

Keywords: Action Game, Formal Game Element, Rhythm Fighting Game, Video Game

\section{INTRODUCTION}

Action game is the types of games with simple gameplay and many varieties of easy-to-use features, so there is minimal risk of players getting confused. The purpose of the action game is clear, simple and the difficulty of achieving the goal is determined by the player's talent [1]. Action game has various subgenres, fighting and rhythm fighting are two of them. A fighting game is fighting or duel against a computer or other players [7]. A rhythm game is a game of pressing buttons according to computer instructions [6]. There was a collaboration between the two subgenres to changes in features and elements. However, Xiong's research [7] reveals that with a very short game duration and difficult accuracy, fighting gameplay makes it difficult for players to get entertainment.

In contrast to rhythm games, which is increasingly in demand, many players even become addicted. Therefore, this update makes a new design, where fighting game uses rhythm game gameplay while maintaining its fighting game mechanic. Hence, this collaboration is called the rhythm fighting game (RFG).

The hallmark of rhythm fighting games appears from its elements that produce gameplay similarities with different game mechanics. Characteristics are 
seen from comparisons using formal game elements that identify various aspects. There are players, objectives, procedures, rules, resources, conflicts, limitations and goals. Rhythm fighting games can be played via mobile, computer, or Nintendo. On Android phones, there is a game called Welcome to The Factory, which can be downloaded for free on the Playstore. Rhythm Fighter for computer players can be purchased at various Market Places, and Skybolt Zack for Nintendo players can be purchased on the official Nintendo website. The three games are rhythm fighting games with different themes and limitations but have the same player interaction, plot, story, gameplay, attack accuracy, and the same result. Many similarities with various additional elements have made many players addicted to playing RFG from the past until now. Some players even have become loyal fans.

\section{LITERATURE REVIEW}

\subsection{Action Fighting Game}

A fighting game is a battle game with two types. The first type is a battle between 2 characters, and the second is a battle between 1 or more characters against multiple characters. Fights can use bare hands like boxing or weapons like pistols, swords, sticks, and others to resemble the real world of martial arts. Movements in fighting games are usually displayed with hyperbole effects that dramatize the appearance of the character. Fighting games depend on the physical skills of the players, the player's reaction and timing. In fighting games, many types of movements are shown by attack and defence movements. Players must move correctly to make effective moves and earn points to pass the level successfully. Fighting games also feature combo moves or multiple moves displayed at a time. The development and innovation of fighting games lie in their challenges. The designer creates extra challenges to make the game more various includes character actions and reactions, character interactions with other characters, in-game environments, backgrounds, character reactions to injuries, and in-game controls.

\subsection{Action Rhythm Game}

Rhythm games are everyone popular game because it's easy to learn but difficult to win. The way to play is the player press the button while following the rhythm that the computer determines and sequenced on the screen and must still focus on the movement and background music [6]. Games require coordination between eyes, ears, and hand speed. The point or score will increase in this game depends on the accuracy and the player's speed. Rhythmic games provide a different experience for players. The existence of stimuli to improve motor and cognitive functions makes players more active and focused, so it's not only the involvement of players but also the learning provided. Rhythm games have various advantages that keep players "stuck" for years to keep looking for new versions of rhythm games with new themes. This game can be a casual or competitive game, depending on the theme and objectives [8].

The advantage of rhythm games is that this game can be played by all ages, from children to the elderly [4]. Since the gameplay is easy, the games are not changed from the past. The rhythm game mechanism makes players sensitive to rhythm and time concepts. Players automatically respond to find patterns in a short time and focus on the visuals displayed. Rhythm Games can also develop hand-eye coordination because rhythm games are filled with various elements shown on the screen and can be used. Rhythm, timing, and computer directions to be followed by players making vision, reflexes, and decisions players create patterns and coordination between eyes and hands. Motor and cognitive functions can train because rhythm games can challenge the player's sense of taste [8]. The player's skill in pressing different buttons in different directions also makes the player's fingers move in a short time while listening to the rhythm of the background music. Cognitive development lies when players integrate the structure of previous behavior patterns into new, more complex behavior patterns [5], where differences influence the stage of development in motor function between players. Rhythm Games can help learning and therapy because the forms and themes are very diverse.

\subsection{Formal Game Elements}

The method to analyze and dissect the rhythm fighting game uses the Content Analysis method from Harold D. Lasswell. Methods were introduced to analyze symbols and interpret them [3]. Researchers get the data in the communication displayed by the object of analysis in signs, logos, symbols, and other visual elements. This makes the content analysis method can be used to analyze various forms of communication such as images, videos, applications and games. The basis of the analysis uses the game element theory from Fullerton. These elements are components that must be considered when designing a game. There are two types, formal elements and dramatic elements. 
Formal game elements build the game's structure [2] with several important parts; there are players, objectives, procedures, rules, resources, conflicts, boundaries, and goals. Formal game elements are physical elements needed in designing a game to be played and entertained by the players. This is an explanation of the formal elements of the game:

The first is the Player aspect. The person who plays the game. The player is main element in the game because the game runs depending on what the player chooses. The important things are the number of players, the role of players, and the interaction of players with the game. The second is the objective aspect, reasons of the player to continue playing the game. The objective must be achievable by the player and the way to achieving the goals. The player is involved with various challenges and obstacles in the game. The third is the procedure aspect, how the players achieve goals in the game. The procedure is how characters get points, ways to fight enemies, find clues, and another way that depends on the game being played. The fourth is the rule aspect, various things that players can do. The rules must be clear, so players are directed and not confused to achieve goals in the game. The fifth is the resource aspect, the assets or equipment that players use to achieve goals. These resources can help or make the player lose, depending on how the player uses the resource.

The sixth is the conflict aspect. Obstacles that prevent the game from running smoothly. Conflicts appear as obstacles when the player tries to achieve a goal. The conflicts are designed as rules, boundaries, or procedures that make players struggle or experience dilemmas to attain goals. The seventh is the boundaries aspect, separator between real life and fantasy shown in the game. An example is when humans can fly in the game. This is acceptable as part of the game, but not in the real world. The eighth is the goal aspect, which is earned when the player reaches a goal in the game. This can be seen clearly and cannot be guessed by the players. The result in the game isn't always in the form of a win; the designer can make the ranking or the total score.

\section{METHOD AND DISCUSSION}

This research uses the Content Analysis Method. The research was conducted by paying attention to players who play rhythm fighting game genre games and playing the game directly. The game chosen for analysis is a rhythm fighting game that shows stories and problems of the games' main character to push players to play the game and achieve goals. The chosen game is also a game downloaded from the application store on mobile phones or computers. The games are released in 2020 and 2021.

The games used as case studies to analyze the formal game elements of the rhythm fighting game are Welcome to The Factory, which can be played on Android; Rhythm Fighter, which can be played on computers; and Skybolt Zack, which can be played on Nintendo. These three RFG represent various platforms that many people love. Therefore, this analysis aims to obtain a comparison that can represent various types of rhythm fighting games. This is the explanation of the comparative analysis of the three RFG.

\subsection{Players}

The 3 RFGs are played and intended for 1 player who fights to beat the opponent controlled by the computer. In addition, rhythm Fighter and WTF allow players to increase character strength.

Table 1. Players

\begin{tabular}{|l|l|l|}
\hline Rhythm Fighter & WTF & Skybolt Zack \\
\hline 1 role for 1 player & 1 role for 1 player & 1 role for 1 player \\
\hline \begin{tabular}{l} 
Single-player vs computer \\
\hline $\begin{array}{l}\text { Player as an animal to fight zombies and } \\
\text { save the world. Players can buy support } \\
\text { equipment with coins after winning levels }\end{array}$
\end{tabular} & $\begin{array}{l}\text { Player as a robot trying to get out of the } \\
\text { factory by defeating various enemies Players } \\
\text { can buy support equipment with coins after }\end{array}$ & $\begin{array}{l}\text { Player as a human-robot who defeats } \\
\text { other rots for revenge }\end{array}$ \\
\hline
\end{tabular}




\begin{tabular}{|l|l|}
\hline in the game & winning levels in the game \\
\hline
\end{tabular}

\subsection{Objectives}

The objective of the 3 RFG games is the same, defeating various enemies to achieve each character's goals with different powers and supporting equipment. Rhythm Fighter and WTF make players easier to pass levels by buying supporting equipment with coins. The purpose of 3 RFG is the same as the real world. Human life aims to win by passing through various obstacles that must be conquered and given in it. These obstacles keep players motivated and curious about the next challenge.

Table 2. Objectives

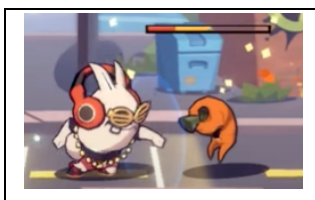

Rhythm Fighter
Reach the highest level and get all the characters

Against various high-level enemies

Can buy weapons with coins making it easier to fight enemies

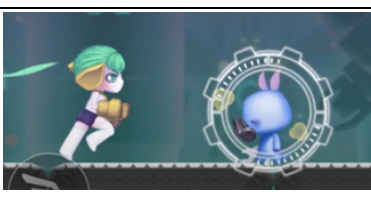

WTF

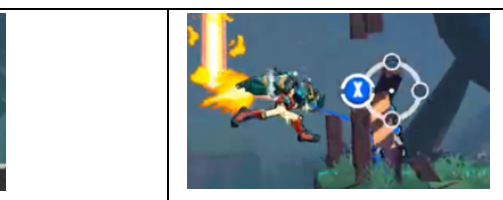

Skybolt Zack

Reach the highest level and break the speed record

Against various high-level enemies

\subsection{Procedures}

Aspect procedure 3 RFG starts from the starting action section when the 3 games present 1 initial character for players and place the tutorial at the first level. Tutorials are important to do for the convenience of playing. Three games provide the experience of defeating the enemy with a low level of difficulty. The next part is a progression of action when many obstacles, strength, and speed of the enemy increases. Some hints appear in the middle of the game. This is useful for preventing player confusion. But Rhythm Fighter and WTF provide hints by pausing the game suddenly and showing quite long text, disrupting the player experience. Although, in contrast to Skybolt Zack, it displays clear size and bright color fonts in addition to characters without pausing the game, players still enjoy the game while getting additional information. The special action part of this 3 RFG is that it allows players to get additional lives. This is a positive thing because players can play the game longer, and it isn't easy to give up. The advantage is in WTF, where players can collect various kinds of game accompaniment songs and can arrange them so that the background song can become the player's favorite song. The resolving action in the 3 games is the same, continuing to the next level with a harder challenge.

Table 3. Procedures

\begin{tabular}{|l|l|l|l|}
\hline \multirow{5}{*}{ Starting action } & 1 character for the player & 1 character for the player & Skybolt Zack \\
\cline { 2 - 4 } & Tutorial in the first level & Tutorial in the first level & Has two tutorial levels \\
\hline
\end{tabular}




\begin{tabular}{|l|l|l|l|}
\hline & weapons to earn points and money. & by hitting and jumping on them. & with robotic powers in his hands. \\
\hline $\begin{array}{l}\text { Progression of } \\
\text { action }\end{array}$ & $\begin{array}{l}\text { Points allow the player to unlock } \\
\text { the next level and money to get } \\
\text { other characters and weapons that } \\
\text { can be used. In the game, players } \\
\text { will be assisted by gods with } \\
\text { information in the form of text } \\
\text { balloons. }\end{array}$ & $\begin{array}{l}\text { Some moments allow the } \\
\text { character to fly and avoid some } \\
\text { barriers. Sometimes there is a } \\
\text { female robot appears to provide } \\
\text { information and instructions via text } \\
\text { in word balloons. }\end{array}$ & $\begin{array}{l}\text { Avoid some barriers and keep } \\
\text { the time tempo to hit the speed } \\
\text { record. Hints appear suddenly } \\
\text { during the game in the form of } \\
\text { short words next to the character. } \\
\text { The flow of the game is forward } \\
\text { which does not allow players to } \\
\text { rewind }\end{array}$ \\
\hline Special Action & $\begin{array}{l}\text { There are additional lives when the } \\
\text { player finds the treasure box }\end{array}$ & $\begin{array}{l}\text { Simultaneously, the female robot } \\
\text { will emit light; when the player gets } \\
\text { the light, the character's life will } \\
\text { increase. Players can choose the } \\
\text { variety of music obtained when } \\
\text { successfully continuing the level }\end{array}$ & $\begin{array}{l}\text { There are additional lives that are } \\
\text { obtained when the character } \\
\text { manages to destroy the first aid } \\
\text { box that appears in the game. }\end{array}$ \\
\hline Resolving Action & $\begin{array}{l}\text { Successfully defeat the zombie boss } \\
\text { at the end of each level and defeat } \\
\text { the god of evil at the last level }\end{array}$ & $\begin{array}{l}\text { Successfully defeat the evil fairy } \\
\text { robot at the end of each level }\end{array}$ & $\begin{array}{l}\text { Managed to destroy the iron door } \\
\text { and advance to the next level }\end{array}$ \\
\hline
\end{tabular}

\subsection{Rules}

The rule in RFG is that players must have tempo discipline to conquer the enemy and successfully follow advanced gameplay that doesn't allow players to back down. Players must avoid enemy bodies and weapons, so the life bar isn't reduced. In the Rhythm Fighter, players must have strategized for efficient use of weapons.

Table 4. Rules

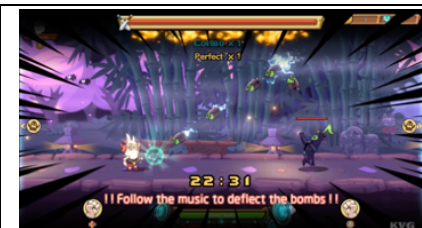

Rhythm Fighter

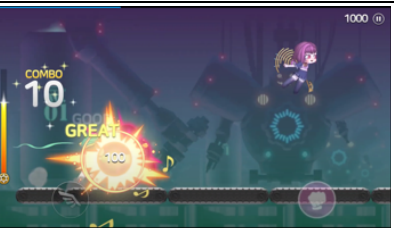

WTF

Players carry out attacks by The accuracy of the attack is based on following the tempo, rhythm of the background music and the line under the character. The player can attack when the line touches the enemy.

\section{If the opponent's weapon or a bullet hits, the} character will lose some lives
Players can attack enemies or pass them. The player must adjust the exact distance so that the attack on the enemy can be accurate

If the enemy's weapon or body hits the character, the character will lose a life
The flow of the game is forward and not allow players to rewind

The use of additional special weapons is limited. Players must have a good strategy
The flow of the game is forward and not allow players to rewind

There are no points when the player has passed the enemy

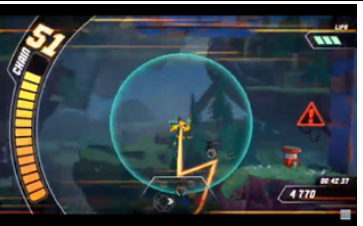

Skybolt Zack

Players can destroy enemies and earn points if they manage to match the buttons on the console and the color of the enemy quickly and may not be able to stop

Players have to hurry. There is a trap in the form of some large holes that will make it difficult for players to run out of time and must avoid traps to protect their life

The flow of the game is forward and not
allow players to rewind

The assistance provided can help or make players lose quickly

All enemies must be conquered, impassable 


\subsection{Resource}

WTF resources are only focused on providing longer playing opportunities for players who have a lot of coins. This creates boredom and makes this game not ideal for playing for a long time because it only focuses on the speed of the challenge. Skybolt Zack has few resources because character development is in line with levelling up; uniquely, the trampoline in this game allows players to be helped or even lost, making the game more fun. Rhythm Fighter has the most resources, makes players curious and motivated to unlock the next level and get other resources. Players like to play longer and for a long period.

Table 5. Resource

\begin{tabular}{|c|c|c|c|}
\hline & 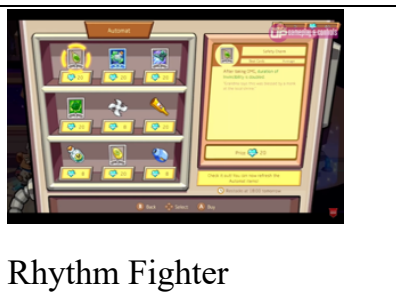 & 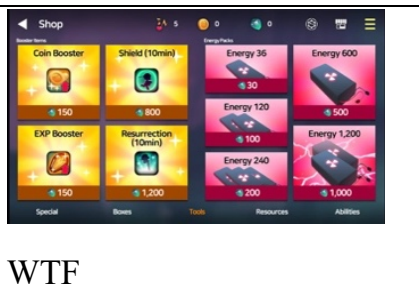 & (6) \\
\hline Lives & $\begin{array}{l}\text { Lives are earned through } \\
\text { destroying treasure chests }\end{array}$ & $\begin{array}{l}\text { Given by fairy and Purchasing with } \\
\text { crystals or coins }\end{array}$ & $\begin{array}{l}\text { Obtained by destroying the first aid } \\
\text { kit }\end{array}$ \\
\hline Currency & $\begin{array}{l}\text { Money to get other characters and } \\
\text { weapons }\end{array}$ & $\begin{array}{l}\text { Money to get live, energy, Music, } \\
\text { Ease of passing levels }\end{array}$ & \\
\hline Time & $\begin{array}{l}\text { Players with long moves will } \\
\text { quickly lose }\end{array}$ & $\begin{array}{l}\text { Players with long moves will } \\
\text { quickly lose }\end{array}$ & $\begin{array}{l}\text { Quick response from players needed } \\
\text { to set a record. }\end{array}$ \\
\hline Terrain & $\begin{array}{l}\text { Horizontal. Exploring the broken } \\
\text { earth. }\end{array}$ & Horizontal. Exploring the factory & $\begin{array}{l}\text { Horizontal and vertical. Explore robot } \\
\text { planets and basements }\end{array}$ \\
\hline Object & $\begin{array}{l}\text { - Weapons } \\
\text { - Treasure Box }\end{array}$ & - Fairy's light & $\begin{array}{l}\text { - First aid box } \\
\text { - Trampolines }\end{array}$ \\
\hline
\end{tabular}

\subsection{Conflict}

Rhythm Fighter has more complex conflicts than Skyboltz Zack and WTF. For example, Skybolt Zack has a conflict where aids can become weapons that turn against players, while WTF lacks conflict because of monotonous enemies and lack of visual resources.

Table 6. Conflict

\begin{tabular}{|l|l|l|l|}
\hline & $|l| l \mid$ & \\
Rhythm Fighter & WTF & Skybolt Zack \\
\hline
\end{tabular}




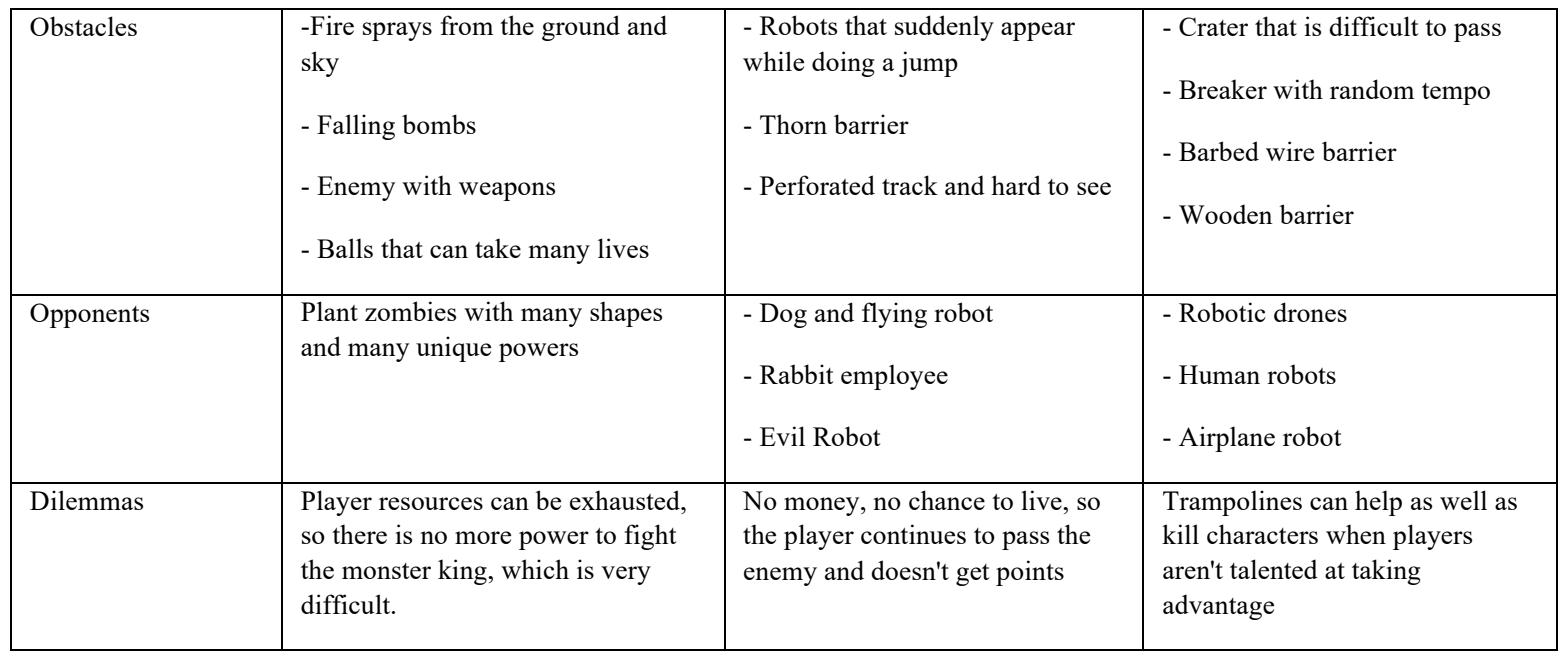

\subsection{Boundaries}

Equality is shown at the limit in the Rhythm Fighting Game, where the character depends on their tool or power. However, the limitations on Rhythm Fighter and Skybolt Zack are just a little so that the imagination and fantasy of players can expand. In contrast to Welcome to The Factory, which has various limitations, so the game is monotonous.

Table 7. Boundary

\begin{tabular}{|l|l|l|}
\hline $\begin{array}{l}\text { Rhythm Fighter } \\
\text { The shape of the characters is a collaboration with } \\
\text { the human skeleton }\end{array}$ & $\begin{array}{l}\text { Monotonous background } \\
\text { To other variation of power other than } \\
\text { human strength and equipment }\end{array}$ & $\begin{array}{l}\text { You can't make a move when a } \\
\text { character doesn't manage to jump at } \\
\text { the right time. }\end{array}$ \\
$\begin{array}{l}\text { Hyperbole effect appears when characters are } \\
\text { attacked }\end{array}$ & $\begin{array}{l}\text { Difficult lives increase } \\
\text { Shent }\end{array}$ & \\
\hline
\end{tabular}

\subsection{Goals}

The rhythm fighting game is about defending your life to keep beating your enemies and winning the game. But in contrast to Skybolt Zack, it challenges players in speed record competition with other players. 
Table 8. Goals

\begin{tabular}{|l|l|l|}
\hline Rhythm Fighter & WTF & Skybolt Zack \\
\hline Win & Win & Win and Hit speed record \\
\hline
\end{tabular}

\section{CONCLUSION}

The similarities that characterize the advantages that can attract and retain players and the shortcomings that hinder players from the RFG are shown through the formal elements of the game as an important element forming the game structure with eight aspects in it. The player aspect shows that one player can only play the 3 RFGs against a computer opponent. Another advantage is Rhythm Fighter, which presents various characters so that players are curious to use other characters. In contrast, the other two games only have one character that can be played until the end. The objective aspect of the 3 RFGs is the same, which is about defeating the enemy with the strengths of the characters that characterize RFG. Similarities also appear in the aspect of the procedure where at the beginning of the game, the three games present tutorials to add to players' convenience. In addition, the three games also display instructions in the game to minimize confusion. Weaknesses exist in Rhythm Fighter and WTF because the instructions displayed seem a lot, so that it pauses the game and can potentially reduce player comfort. The design of the Skybolt Zack's guide is ideal because it is minimalist in design, so it doesn't interfere with comfort. The advantages also appear with additional lives for players that increase the duration of the game. Unfortunately, WTF is stingy in giving lives so that players are easy. Finally, all three games have the same ending, continuing to the next level with more complicated challenges.

Rule aspects of the 3rd RFG also the same. Players must focus and maintain the tempo to win because the game flow is advancing and doesn't allow players to back. The ideal Resource aspect of the three games is the addition of lives, additional weapon variations, a collection of character variations that make players curious and motivated, as presented by Rhythm Fighter. The advantage is also in Skybolt Zack, which presents resources with a boomerang effect that adds challenge for players. WTF only has few resources, but it allows players to collect their favourite songs. The Conflict aspect in the three games is different. Rhythm Fighter and Skybolt Zack have complex conflicts, so players focus and get lost in them, but WTF shortcomings. The visualization of monotonous obstacles and less visible tracks makes players bored and quickly lose. Limitations aspects of Rhythm Fighter are few, this game displays many visualization effects and character variations movements, so it brings up players' imagination and fantasy. WTF and Skyboltz Zack show weaknesses by limiting character skills, so players are often trapped and then give up. The Goals aspect is the display of goals in Rhythm Fighter with additional animated videos. WTF only displays simple animations. In contrast, Skybolt Zack displays animated videos and speed records from players around the world. The advantage is in Skybolt Zack that takes advantage of the ambitious nature of its players with a record concept that makes this game become a long-term game.

To design the RFG genre, designers can collaborate on the characteristics and advantages of the three games. The last thing that is most important in designing an RFG is how the designer determines the theme and presents various features, so players play the game for a long time.

\section{REFERENCES}

[1] Adams, E., \& Joris, D. Game Mechanics: Advanced game Design. Berkeley: New Riders games.; 2012

[2] Fullerton, T. Game Design Workshop. 2nd edition. USA: Elsevier, 49.2008

[3] Suprayogo, I. Metodologi Penelitian SosialAgama, Bandung: Remaja Rosdakarya, 6. 2001 
[4] Erik., \& Aldian, R. Pembuatan Rhythm game Pada Android Menggunakan Aplikasi Construct 2 (Studi Kasus: Game Symphony Angklung). Konferensi Nasional Sistem Informasi 2018, 856-863. 2018

[5] Jefri. Penerapan Model Pembelajaran Kooperatif tipe Numbered Heads Together (NHT) dengan Menggunakan Media Gambar untuk Meningkatkan Hasil Belajar Kognitif Biologi Siswa Kelas VII.4 SMPN 1 Pantai Raja Kabupaten Kampar Tahun Ajaran 2016/2017. Tesis. Program Studi Biologi Universitas Islam Riau, 5. 2017

[6] Song, D. Analysis and evaluation of mobile rhythm games: game structure and playability. International Journal of Electrical and Computer Engineering (IJECE), 5263. 2019

[7] Xiong, S. Long Z., Zeliang Z., \& Shuo, Z. Elearning Rhythm Design. Case Study Using Fighting games. E-Learning and games: 12th International Conference, 293-302. 2019

[8] Brown, J. What Makes Rhythm Games So Successful?. Game Green [serial online]. 2014. Available from: https://www.gamegrin.com/articles/what-makesrhythm-games-so-successful/ 